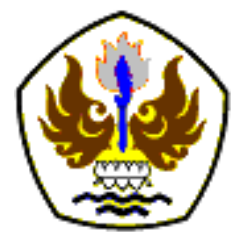

INFOMATEK

Volume 22 Nomor 2 Desember 2020

\title{
ANALISA PENGARUH KETEBALAN PADA KAMPUH BILAH GANDA DAN DIAMETER RIVET TERHADAP KEKUATAN SAMBUNGAN PADA BEBAN AKSIAL
}

\author{
Wahyudi, Aa Santosa ${ }^{\star}$, Oleh \\ Program Studi Teknik Mesin \\ Fakultas Teknik-Universitas Singaperbangsa Karawang
}

\begin{abstract}
Abstrak: Penyambungan dengan menggunakan kampuh bilah ganda dan baut atau rivet umumnya digunakan pada plat utama yang mempunyai beban yang besar. Kerusakan yang terjadi pada kampuh bilah ganda terjadi pada plat sambungan atau rivet karena adanya gaya eksternal berupa tarikan. Tegangan yang terjadi akan mermbat pada lubang plat atau rivet yang memiliki perubahan geometri. Telah dilakukan sebuah penelitian untuk mengetahui sifat mekanik material pelat yang dikenai gaya tarik sebesar $25 \mathrm{KN}$ dengan arah horisontal, Material uji yang akan disimulasikan adalah material structural st 37 dengan kekuatan tarik luluh $362 \mathrm{MPa}$ untuk material plat atau kampuh penyambung. Materil rivet menggunakan st 30 dengan kekutan tarik sebesar $290 \mathrm{MPa}$ dan untuk materil plat utama menggunakan AISI $1045 \mathrm{C}$ dengan kekuatan tarik sebesar $450 \mathrm{Mpa}$. Simulasi ini menggunakan Software Ansys. Untuk ukuran Diameter rivet yang digunakan dalam simulasi ini adalah ada 3 jenis yaitu $\mathrm{Dr}=12 \mathrm{~mm}, 14 \mathrm{~mm}$ dan $16 \mathrm{~mm}$ sedangkan untuk tebal kampuh tp =6 mm, $8 \mathrm{~mm}$ dan $10 \mathrm{~mm}$. Tegangan maksimum yang terjadi pada kampuh atau rivet lebih kecil dibandingkan dengan tegangan yang terjadi pada plat utama. Sehingga kemungkinan terjadi kegagalan lebih besar pada plat utama. Untuk rivet yang dengan ukuran diameter $12 \mathrm{~mm}$ dan ketebalan kampuh $6 \mathrm{~mm}$ tegangan maksimum yang terjai masih dibawah tegangan plat utama.
\end{abstract}

Kata kunci: Sambungan, Rivet, Beam, Bilah Ganda, Kampuh

\section{PENDAHULUAN}

Penyambungan beam dengan menggunakan kampuh (butt joint) adalah salah satu bentuk penyambungan yang banyak ditemukan dalam konstruksi jembatan, menara atau struktur lainnya (Pinem [1]). Ukuran sambungan yang digunakan disesuaikan dengan kemampuan bahan dasar, beban

*) aa.santosa@ft.unsika.ac.id

Pertama diterima: 8 September 2020

Direvisi: 13 November 2020

Disetujui untuk publikasi: 15 November 2020 eksternal yang ada serta bahan dari kampuh dan rivet itu sendiri. Jumlah rivet yang digunakan juga harus disesuaikan beban yang akan ditumpunya. Jika jumlah rivet yang digunakan terlalu banyak juga akan menimbulkan stress pada sambungan itu sendiri.

Sebagai bagian utama dalam penyambungan, kemampuan kampuh bilah ganda (double strap butt joint) dan rivetnya yang digunakan 
harus memiliki konstruksi yang standar perancangan. Pengaruh ketebalan kampuh dan diameter rivet akan menentukan kemampuannya dalam menyambungkan bagian tersebut (Servi [2]). Kombinasi unsur tersebut akan mempengaruhi juga terhadap penilaian tegangan secara keseluruhan terutama pada penyebaran tegangan yang terjadi. Tegangan yang muncul pada bagian tertentu akan merambat kebagian lainnya sehingga kemungkinan terjadi kegagalan pada sambungan [1].

Adanya kombinasi yang rumit dari kedua unsur yaitu kampuh dan diameter rivet yang digunakan, setiap orang dapat menentukan ukuran sesukanya tanpa memperhatikan rambatan tegangan pada kampuh maupun rivet. Pada kesempatan ini, penulis akan menganalisa pengaruh kombinasi ketebalan plat kampuh bilah ganda dan ukuran diameter baut terhadap kekuatan sambungan. Sehingga setiap pengguna dapat menggunakan hasil ini dalam hal penyambungan menggunakan kampuh (Kannapan [3]).

\section{METODOLOGI}

\subsection{Diagram Alir Penelitian}

Pelaksanaan Penelitian ini dimulai dengan menentukan jenis beban pada pelat yang selanjutnya dilakukan analisis dengan menggunakan software Ansys https://www. autodesk.com ([4]).

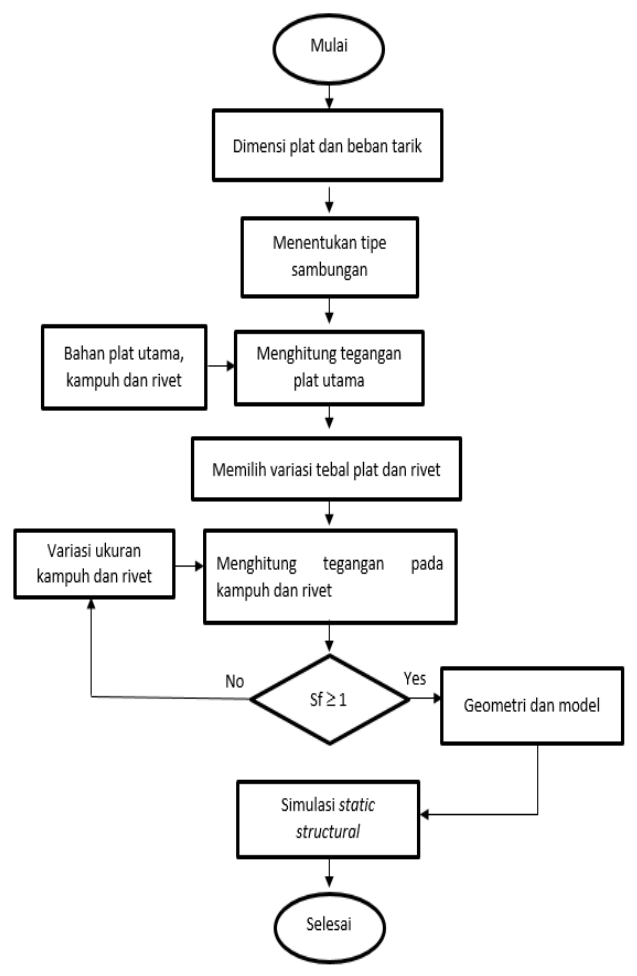

Gambar 1.

Diagram Alir Penelitian

Komponen sambungan yang dianalisa adalah tipe kampuh bilah ganda (double trap butt joint) terdiri dari dua buah plat utama, dua buah plat penyambung (kampuh) dan beberapa buah rivet. Selain itu juga kedua plat utama dikenakan gaya tarik aksial sebesar 25 kN dari kedua ujung-ujungnya secara static. Plat utama mempunyai ukuran lebar $145 \mathrm{~mm}$ dan ketebalan $10 \mathrm{~mm}$. sementara diameter rivet divariasikan mulai dari $12 \mathrm{~mm}, 14 \mathrm{~mm}$ dan $16 \mathrm{~mm}$. Sedangkan jumlahnya ditentukan berdasarkan pada beban tarik yang terjadi. 
Untuk variasi ketebalan kampuh bilah ganda ditentukan sebesar $6 \mathrm{~mm}, 8 \mathrm{~mm}$ dan $10 \mathrm{~mm}$.

Material uji yang akan disimulasikan adalah material structural st 37 dengan kekuatan tarik luluh $362 \mathrm{MPa}$ untuk material plat atau kampuh penyambung. Materil rivet menggunakan st 30 dengan kekutan tarik sebesar $290 \mathrm{MPa}$ dan untuk materil plat utama menggunakan AISI 1045 C dengan kekuatan tarik sebesar $450 \mathrm{MPa}$ Data teknis material dapat dilihat dalam table berikut (Kalpakjan [5]).

Tabel 1. Karakteristik komponen Pelat

\begin{tabular}{|c|l|c|c|}
\hline No & Komponen & Simbol & Nominal \\
\hline 1 & Plat utama & $\sigma_{\mathrm{y} 1}$ & $450 \mathrm{MPa}$ \\
\hline 2 & Plat kampuh & $\sigma_{\mathrm{y} 2}$ & $360 \mathrm{Mpa}$ \\
\hline 3 & Rivet & $\sigma_{\mathrm{y} 3}$ & $290 \mathrm{MPa}$ \\
\hline
\end{tabular}

Geometri sambungan kampuh bilah ganda digunakan memilki ukuran lebar 145 mm dan panjang $160 \mathrm{~mm}$. Jumlah kampuh yang digunakan sebanyak 2 buah sebagai penjepit plat utama. Jarak antara lubang rivet digunakan tetap sebesar $35 \mathrm{~mm}$. Gaya yang bekerja sejajar dengan plat utama

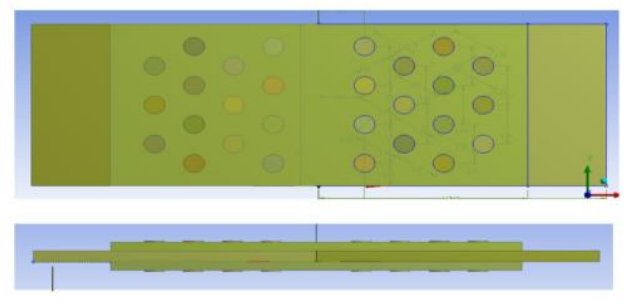

Gambar 2.

Susunan Sambungan Pelat
Untuk gaya penarikan digunakan gaya sebesar $\mathrm{F}=20 \mathrm{kN}$ arah mendatar. Diameter lubang sambungan ditentukan sebesar 12 $\mathrm{mm}, 14 \mathrm{~mm}$ dan $16 \mathrm{~mm}$ dengan ketebalan plat $6 \mathrm{~mm}, 8 \mathrm{~mm}$ dan $10 \mathrm{~mm}$. Dalam table 2 berikut disajikan variable bebas dan parameter penelitian pengaruh jarak lubang.

Tabel 2. Variabel pipa berlubang

\begin{tabular}{|c|c|c|c|c|}
\hline Kode & $\begin{array}{c}\text { Variable/ } \\
\text { Parameter }\end{array}$ & $\mathbf{1}$ & $\mathbf{2}$ & $\mathbf{3}$ \\
\hline $\mathrm{Tp}$ & $\begin{array}{c}\text { Tebal plat } \\
\text { kampuh (mm) }\end{array}$ & 6 & 8 & 10 \\
\hline $\mathrm{Dr}$ & $\begin{array}{c}\text { Diameter rivet } \\
(\mathrm{mm})\end{array}$ & 12 & 14 & 16 \\
\hline $\mathrm{F}$ & $\begin{array}{c}\text { Gaya tarik } \\
(\mathrm{kN})\end{array}$ & 20 & - & - \\
\hline $\mathrm{DI}$ & $\begin{array}{c}\text { Diameter } \\
\text { lubang (mm) }\end{array}$ & follow & follow & follow \\
\hline Tu & $\begin{array}{c}\text { Tebal plat } \\
\text { utama(mm) }\end{array}$ & 10 & - & - \\
\hline $\mathrm{L}$ & $\begin{array}{c}\text { Jarak lubang x } \\
(\mathrm{mm})\end{array}$ & 35 & - & - \\
\hline $\mathrm{C}$ & $\begin{array}{c}\text { Jarak lubang y } \\
\text { (mm) }\end{array}$ & 35 & - & - \\
\hline
\end{tabular}

\section{ANALISIS DAN PEMBAHASAN}

\subsection{Tegangan pada Plat Utama}

Tegangan yang terjadi plat utama pada bagian yang tidak berlubang dihitung berdasrakan pada tengangan normal yang terjadi akibat gaya tarik. dengan ketebalan.

$$
\sigma_{1}=13.79 \mathrm{MPa}
$$


Tegangan ini berlaku pada setiap kampuh bilah ganda dan rivet dan tegangan tersebut harus dapat ditahan oleh komponen tersbut.

\subsection{Penentuan Jumlah Rivet}

Jumlah rivet yang dipakai untuk mengikat kampuh bilah ganda dan plat utama dihitung berdasarkan pada diameter rivet yang akan digunakan. Pada penelitian ini dimeter rivet dan tebal plat kampuh merupakan variable bebas. Untuk ukuran $\mathrm{Dr}=12 \mathrm{~mm}, 14 \mathrm{~mm}$ dan $16 \mathrm{~mm}$ sedangkan untuk tebal kampuh $\mathrm{tp}=6$ $\mathrm{mm}, 8 \mathrm{~mm}$ dan $10 \mathrm{~mm}$. Tegangan geser yang dialami oleh sejumlah rivet adalah [2]:

$$
\begin{aligned}
\tau_{r} & =\frac{13.79 \mathrm{MPa}}{2} \\
\tau_{r} & =6.896 \mathrm{MPa}
\end{aligned}
$$

jumlah rivet adalah :

$$
n=\frac{2 F}{\sigma_{1} A r}
$$

sehingga jumlah rivet yang digunakan adalah :

$$
n=26 \text { buah rivet }
$$

\subsection{Tegangan Tarik Nominal dan Maksimum}

Berdasarkan pada data dan gambar dimensi sambungan kampuh bilah ganda serta lingkup penelitian pada Bab III untuk tebal plat utama $\mathrm{tu}=10 \mathrm{~mm}$, lebar plat lu $=145 \mathrm{~mm}$, Jarak antar lubang $\mathrm{L}=\mathrm{C}=35 \mathrm{~mm}$, maka tegangan tarik nominal yang terjadi pada kampuh bilah ganda adalah:

$$
\begin{aligned}
& \sigma_{n}=\frac{13.79 \mathrm{MPa}}{2\left(1-\frac{12 \mathrm{~mm}}{35 \mathrm{~mm}}\right)} \\
& \sigma_{n}=10.49 \mathrm{MPa}
\end{aligned}
$$

Sehingga tegangan maksimum yang terjadi pada plat berlubang akibat konsentrasi tegangan pada nomor uji 1 adalah :

$$
\begin{gathered}
\sigma_{m a k}=K_{t g} \sigma_{n} \\
\sigma_{m a k}=24.13 \mathrm{MPa}
\end{gathered}
$$

\subsection{Tegangan Tarik Maksimum Hasil}

\section{Simulasi}

Tegangan tarik maksimum hasil simulasi berdasarkan pada von Mises untuk setiap variasi tebal plat kampuh dan ukuran diameter rivet diperoleh sebagai berikut (Partono [6]).

Diameter rivet $\mathrm{Dr}=12 \mathrm{~mm}$ da tebal kampuh ganda $\mathrm{t}=6 \mathrm{~mm}$

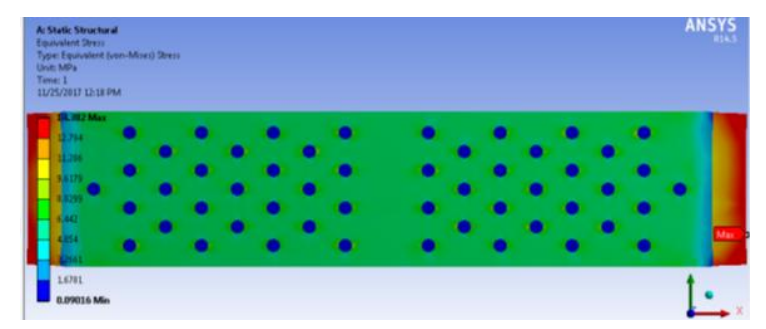

Gambar 3.

Tegangan maksimum pada $\mathrm{Dr}=12 \mathrm{~mm}$ dan $\mathrm{tp}=6 \mathrm{~mm}$

Tegangan maksimum yang terjadi sebesar 14.382 MPa. Hasil perhitungan tegangan maksimum sebesar 24.14 $\mathrm{MPa}$. tegangan 
maksimum terjadi pada plat utama sedangkan pada sambungan tegangan maksimum terjadi sebesar 8.09 MPa.

1. Diameter rivet $\mathrm{Dr}=12 \mathrm{~mm}$ dan tebal kampuh ganda $\mathrm{t}=8 \mathrm{~mm}$

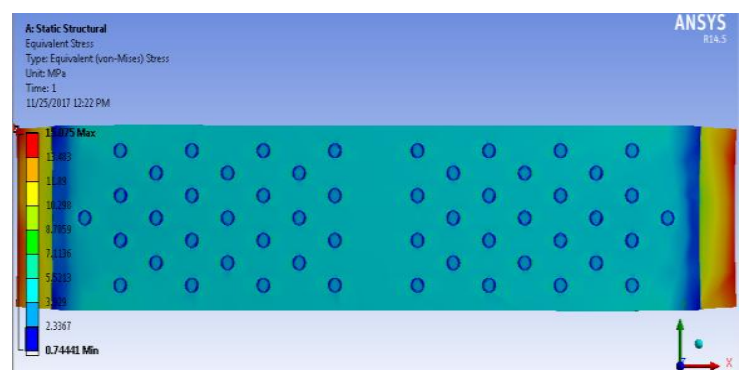

Gambar 4.

Tegangan maksimum pada $\mathrm{Dr}=12 \mathrm{~mm} \& \mathrm{tp}=8 \mathrm{~mm}$

Tegangan maksimum yang terjadi sebesar 14.87 MPa. Hasil perhitungan tegangan maksimum sebesar 25.29 MPa. tegangan maksimum terjadi pada plat utama sedangkan pada sambungan tegangan maksimum terjadi sebesar $10.06 \mathrm{MPa}$.

2. Diameter rivet $\mathrm{Dr}=12 \mathrm{~mm}$ dan tebal kampuh ganda $\mathrm{t}=10 \mathrm{~mm}$

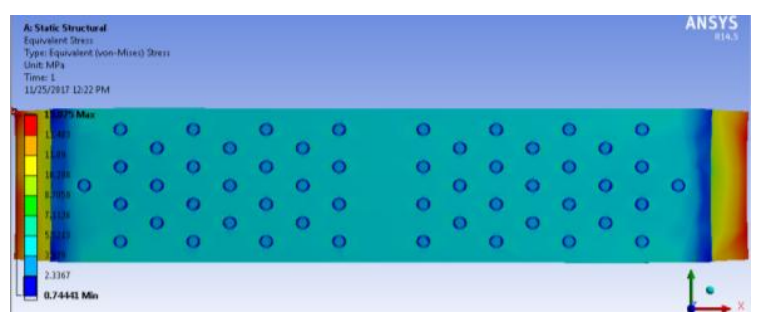

Gambar 5.

Tegangan maksimum pada $\mathrm{Dr}=12 \mathrm{~mm}$ dan $\mathrm{tp}=10 \mathrm{~mm}$
Tegangan maksimum yang terjadi sebesar 15.75 MPa. Hasil perhitungan tegangan maksimum sebesar $27.70 \mathrm{MPa}$. tegangan maksimum terjadi pada plat utama sedangkan pada sambungan tegangan maksimum terjadi sebesar $12.72 \mathrm{MPa}$.

3. Diameter rivet $\mathrm{Dr}=14 \mathrm{~mm}$ dan tebal kampuh ganda $\mathrm{t}=6 \mathrm{~mm}$

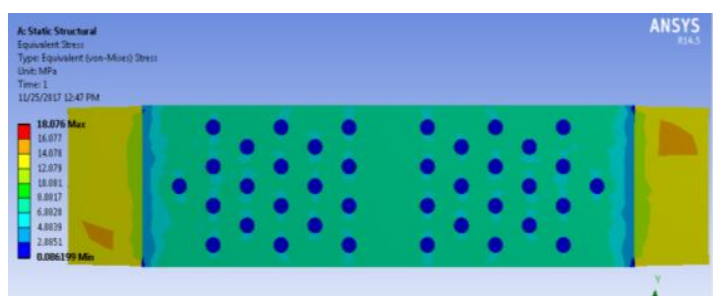

\section{Gambar 6.}

Tegangan maksimum pada $\mathrm{Dr}=14 \mathrm{~mm}$ dan $\mathrm{tp}=6 \mathrm{~mm}$

Tegangan maksimum yang terjadi sebesar 18.08 MPa. Hasil perhitungan tegangan maksimum sebesar 24.12 MPa. tegangan maksimum terjadi pada plat utama sedangkan pada sambungan tegangan maksimum terjadi sebesar $10.02 \mathrm{Mpa}$.

4. Diameter rivet $\mathrm{Dr}=14 \mathrm{~mm}$ dan tebal kampuh ganda $\mathrm{t}=8 \mathrm{~mm}$

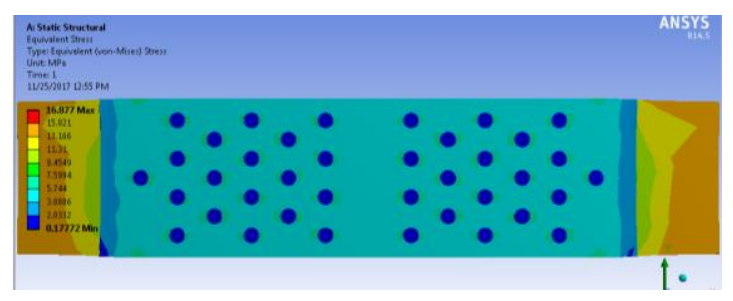

Gambar 7.

Tegangan maksimum pada $\mathrm{Dr}=14 \mathrm{~mm}$ dan $\mathrm{tp}=8 \mathrm{~mm}$ 
Tegangan maksimum yang terjadi sebesar 18.88 MPa. Hasil perhitungan tegangan maksimum sebesar 25.29 MPa. tegangan maksimum terjadi pada plat utama sedangkan pada sambungan tegangan maksimum terjadi sebesar 11.7 Mpa.

5. Diameter rivet $\mathrm{Dr}=14 \mathrm{~mm}$ dan tebal kampuh ganda $\mathrm{t}=10 \mathrm{~mm}$

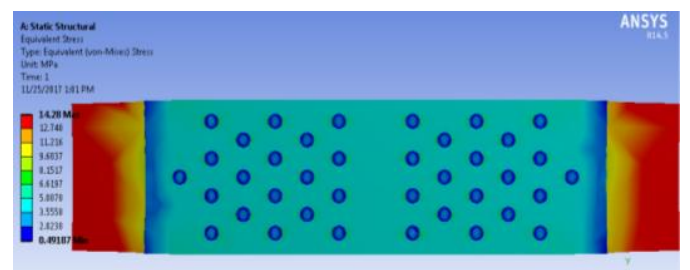

\section{Gambar 8.}

Tegangan maksimum pada $\mathrm{Dr}=14 \mathrm{~mm}$ dan $\mathrm{tp}=10 \mathrm{~mm}$

Tegangan maksimum yang terjadi sebesar 14.28 MPa. Hasil perhitungan tegangan maksimum sebesar 27.70 $\mathrm{MPa}$. tegangan maksimum terjadi pada plat utama sedangkan pada sambungan tegangan maksimum terjadi sebesar $12.72 \mathrm{Mpa}$.

6. Diameter rivet $\mathrm{Dr}=16 \mathrm{~mm}$ dan tebal kampuh ganda $\mathrm{t}=6 \mathrm{~mm}$

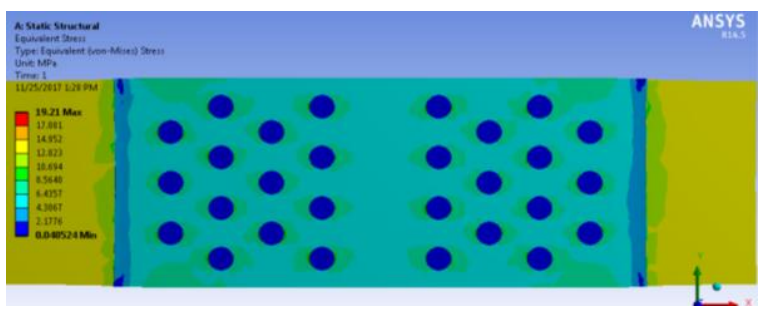

Gambar 8.

Tegangan maksimum pada $\mathrm{Dr}=16 \mathrm{~mm}$ dan $\mathrm{tp}=6 \mathrm{~mm}$
Tegangan maksimum yang terjadi sebesar 15.75 MPa. Hasil perhitungan tegangan maksimum sebesar 27.70 MPa. tegangan maksimum terjadi pada plat utama sedangkan pada sambungan tegangan maksimum terjadi sebesar 5.6 Mpa.

7. Diameter rivet $\mathrm{Dr}=16 \mathrm{~mm}$ dan tebal kampuh ganda $\mathrm{t}=8 \mathrm{~mm}$

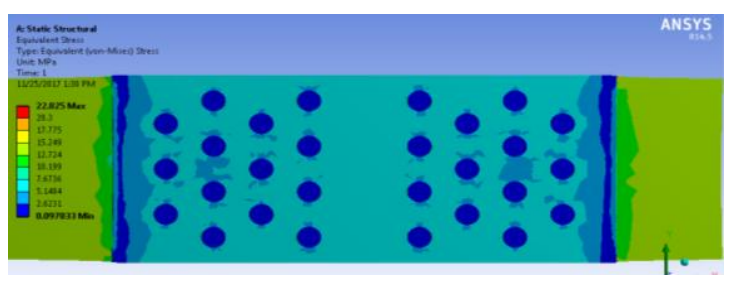

Gambar 9.

Tegangan maksimum pada $\mathrm{Dr}=16 \mathrm{~mm}$ dan $\mathrm{tp}=8 \mathrm{~mm}$

Tegangan maksimum yang terjadi sebesar 22.83 MPa. Hasil perhitungan tegangan maksimum sebesar 25.29 $\mathrm{MPa}$. tegangan maksimum terjadi pada plat utama sedangkan pada sambungan tegangan maksimum terjadi sebesar 7.67 Mpa.

8. Diameter rivet $\mathrm{Dr}=16 \mathrm{~mm}$ dan tebal kampuh ganda $\mathrm{t}=10 \mathrm{~mm}$

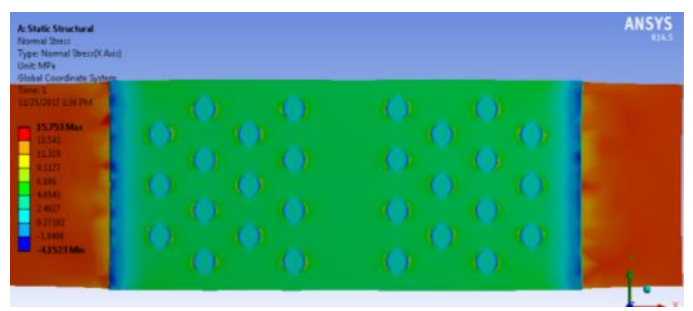

Gambar 10.

Tegangan maksimum pada $\mathrm{Dr}=16 \mathrm{~mm}$ dan $\mathrm{tp}=8 \mathrm{~mm}$ 
Tegangan maksimum yang terjadi sebesar 15.75 MPa. Hasil perhitungan tegangan maksimum sebesar 27.70 MPa. tegangan maksimum terjadi pada plat utama sedangkan pada sambungan tegangan maksimum terjadi sebesar 5.91 Mpa.

\section{KESIMPULAN}

Penyambungan dengan menggunakan kampuh bilah ganda dan baut atau rivet masih banyak digunakan untuk konstruksi maupun pabrikasi. Pemilihan tebal dan diameter baut menjadi salah satu faktor penting dari sebuah sambungan.

Berdasarkan hasil penelitian yang kami lakukan pada sebuah plat kampuh bilah ganda dengan variasi ketebalan kampuh dan diameter rivet. Tegangan maksimum yang terjadi pada kampuh atau rivet lebih kecil dibandingkan dengan tegangan yang terjadi pada plat utama. Sehingga kemungkinan terjadi kegagalan lebih besar pada plat utama. Untuk rivet yang dengan ukuran diameter 12 $\mathrm{mm}$ dan ketebalan kampuh $6 \mathrm{~mm}$ tegangan maksimum yang terjai masih dibawah tegangan plat utama. Pada diameter rivet sebesar $16 \mathrm{~mm}$ tegangan mulai terlihat meningkat tajam pada plat utama dan kampuh. Penurunan luas penampang bidang karena penambahan ukuran diameter rivet meningkatkan terjadinya tegangan.

Untuk faktor keamanan sambungan dan rivet, rata-rata berada diatas 7 dan kondisi sangat amat. Faktor keamanan ini sangat dipengaruhi juga oleh jarak antar lubang dan ketebalan plat kampuh yang digunakan. Semakin besar penurunan luas permukaan bidang normal maka semakin turun faktor keamanannya. Pada hasil terakhir yaitu pengujian no 9, menunjukan bahwa ketebalan dan diameter rivet mempengaruhi faktor keamanan bahan.

\section{DAFTAR PUSTAKA}

[1] Pinem, D. Analisis Struktur dengan Metode Elemen Hingga, 2010, Rekayasa Sains Bandung.

[2] Servi, D. Aplikasi Metode Elemen Hingga Pada Struktur Batang, Jurnal IImiah Media Engineering, Vol 1, No.2. 2011. Universitas Samratulangi.

[3] Kannapan, S. 1986. Instroduction to Pipe Stress Analysis. Jhon Wiley And Sons, Inc., U.S.A.

[4] https://www.autodesk.com/products/ fA nsys/students-teachers-educators, diakses September 2020

[5] Kalpakjan, 1995. Manufakturing Engineering ang Technologi, edisi ke3. Addison-wesley Publishing Company. United States of Amaerica 
Infomatek Volume 22 Nomor 2 Desember 2020 : 69 - 76

[6] Partono, W. Optimasi Distribusi

Jurnal Teknik Undip, Semarang.

Lubang pada Baja Kastella, 2018, 